CHAPTER I 4

\title{
A living heritage approach: the main principles
}

\section{Continuity (criteria)}

A living heritage approach emphasises the recognition of criteria of continuity as primary drivers for the definition, conservation and management of heritage (on the development of a living heritage approach see Poulios 2010a, and Poulios 2011; on the application of Strategic Innovation theory to a living heritage approach see Poulios 2014; on the application of Place Building Theory to a living heritage approach see Kimball et al. 2013; on the application of elements of a living heritage approach to the development of Renewable Energy plants in connection to the protection of historic environments and to the sustainable development of local communities see Poulios 2012a). Specifically:

a) The continuity of the heritage site's original function. A living heritage approach aims at maintaining-sustaining the original function of a living heritage site and, where appropriate, also reviving it in case this has been broken. At Meteora, conservation, in the context of a living heritage approach, would primarily aim at maintaining the continuity of the monastic function of the site, and also at reviving it after periods of monastic absence as those of WWII and the Civil War. The preservation of the fabric would not collide with the safeguarding of the monastic function, but would be embraced within it. This is clearly reflected in the words of a current monk and a current nun at Meteora:

The monks of Meteora did not aim in the first place to create heritage on the hostile rocks. By offering to God the best they could, they rendered heritage the natural outcome of their "first/foremost love" for God. (Tetsios 2003, 338)

And:

We [the monks and nuns] did not come here [to Meteora] to create heritage. We came here to glorify our God, and save ourselves through the glorification of God. Heritage is simply the outcome of the glorification of God. Even if the entire site is destroyed, we should and will still remain here glorifying our God. (pers. comm. Nikodimi) 


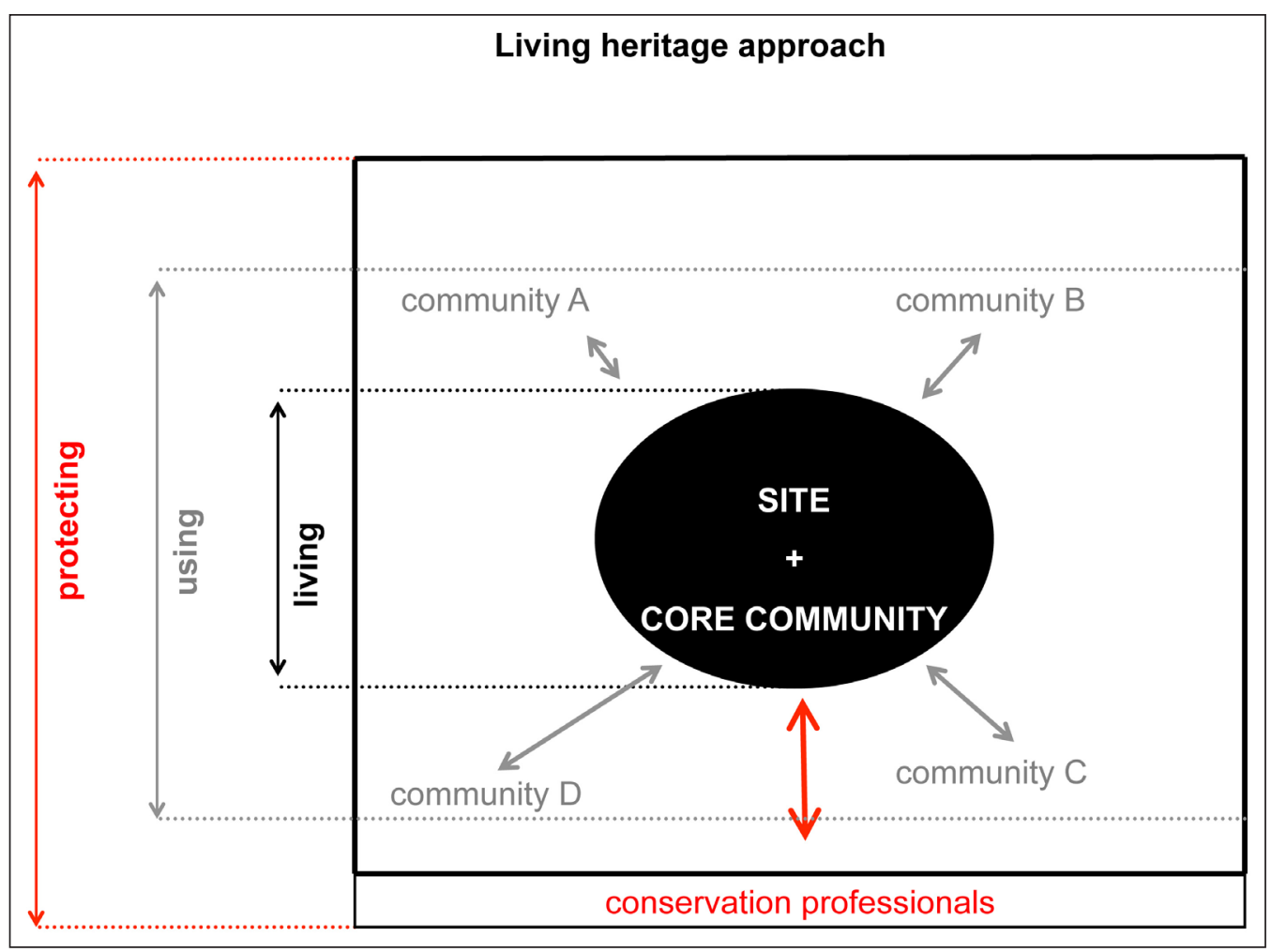

Figure 52: A living heritage approach: core community and heritage site, the broader community, and conservation professionals. Core community is seen as an inseparable part of the heritage site, and is clearly differentiated from the conservation professionals and the broader community. [Note: the 'core community' of a living heritage approach is differentiated from the 'local community' of a values-based approach, which is seen as one of the stakeholder groups: figure 4 in Part 1]. Core community is given the primary role in the conservation process, while conservation professionals provide an enabling framework of support, guidance and assistance to the core community.

b) The continuity of the community's connection with the heritage site. A living heritage approach does not treat all groups (and all values) equally, but forms a hierarchy among them on the basis of their differing associations with the site - in this sense, a living heritage approach may not be considered a 'democratic' approach. A living heritage approach prioritises the core community's connection over the other communities' associations with the site, acknowledging that heritage forms an integral part of the life of the specific community, in that it strengthens core-community's identity, pride, self-esteem, structure, and well-being. On this basis, the core community is given the primary role in the conservation process. The core community does not simply participate in the process but is actively empowered: it has the ability to set the agenda, take decisions, and retain control over the entire process. Conservation professionals and the broader community are given a secondary role, that of providing an enabling framework of support, guidance and assistance to the core community (figure 52). Furthermore, the core community seeks development potentials on the basis of its own connection with heritage and in accordance with its own concerns, with the support of the conservation professionals and the broader community.

Yet, it is important to make clear that a living heritage approach does not allow extreme power to the core community, by setting boundaries to their power within the traditional parameters 
as defined by continuity and in accordance with the original function of the site, also with the support and under the examination of the conservation professionals and the broader community: the core community is not treated as individuals who act on the basis of their personal views, desires and ambitions but as a community that originally created and continues to create the site on the basis of continuity. It is also important to stress that the role of the conservation professionals in the context of a living heritage approach is by no means debased, but is put in a different - and a rather more complicated and demanding - context: the protection of the heritage significance of the site within the traditional parameters as defined by continuity and in accordance with the original function of the sites, in collaboration with the core community and the broader community.

At Meteora, in the context of a living heritage approach, the primary role would be given to the monastic communities, who would be encouraged to continue the creation of the site, with the involvement of the conservation professionals and the broader community through the continual checking of the monastic communities on the basis of the continuity of the site. This is illustrated in the words of a current nun of the site:

The 'better' monks and nuns we become the better heritage we create. But even biologically/as human beings we bear all the positive and negative aspects of the society, the era and the area to which we belong, including family and people, education, culture, and politics. That is why we cannot always lead monastic life in the proper, ideal way, and we do not always do the right things, even on the site itself. That is why there should be some kind of control over our life through a network of laws and experts. For example, spiritual supervision is exercised by the local Bishop, and the control over our restoration and construction works is exercised by the Ministry of Culture. (pers. comm. Nikodimi)

To this end, the manifestation of extreme power on the part of the Roussanou monastic community through the monastery extension, not strictly within the traditional parameters as defined by the Orthodox Tradition on the site, would not be acceptable by a living heritage approach. The widening of the road network of the site that encourages the further development of tourism at the site, at the initiative of the Ministry of Tourism, with the support of the monastic communities and with the consent of the Ministry of Culture, does not seem to be acceptable either. The odd case of the setting of fire to one of the Meteora monasteries by members of the village of Kastraki (because the monks were - claimed to be - seducing girls from their village), may demonstrate, apart from the possible aspect of revenge and certainly in an extreme way, the following: the meaning of Meteora is inextricably linked to the Orthodox Tradition as practiced by the monastic communities (and not to the desires of the monks as individuals), and the broader community has the role of checking the monastic communities on this (this means that, if the monastic communities do not operate within the Orthodox Tradition, there would be no actual reason for the monasteries to exist in the first place).

c) The continuity of the care of the heritage site by the community, as expressed through community's management (and ownership) mechanisms and maintenance practices. In the context of a living heritage approach, conservation process is primarily based on the recognition and acceptance of the traditional care of heritage (by the community); modern scientific-based conservation principles and practices (of the conservation professionals) assist, implement and are placed within the traditional care of heritage. An appropriate equilibrium is sought between heritage use (by the community and in accordance with the community's connection with heritage) and heritage protection (by conservation professionals), with emphasis often on use rather than protection. Although the fabric is generally preserved (as in the context of a material-based approach: see ICOMOS 1964; see Part 1), at the same time there is an increasing recognition of a whole series of practices towards heritage, with little respect to the material, physical structure (see above). 
Thus, in certain occasions heritage may be treated as a 'renewable' resource. On the basis of the core community's care of heritage, coupled with the reduced dependency on external funding and resources, a living heritage approach may be seen as an approach of increased sustainability. At Meteora, a living heritage approach would favour the continuation of the renewal of the individual architectural parts incorporated in harmony within the architectural type of a monastery by the monastic community, with the support of the conservation professionals.

d) The continual process of evolving tangible and intangible heritage expressions / of the evolving space of the site. A living heritage approach sees and safeguards tangible and intangible heritage expressions as an inseparable whole, and embraces the evolution of heritage expressions, rendering them revenant to the contemporary society. Therefore, in the context of a living heritage approach, the core community continues the process of the creation of the space of a living heritage site on the basis of the original function of a site, with the constant support of the conservation professionals and the broader community. At Meteora, a living heritage approach would call for the continual process of evolving space on the basis of the Orthodox Tradition by the monastic communities with the support of the conservation professionals.

\section{The way continuity has evolved over time to present}

A living heritage approach studies and manages the way continuity (all criteria) has evolved over time to present, in an attempt to guarantee the relevance of heritage to the contemporary society. To this end, a living heritage approach would take the following steps: a) identify the factors (the broader changing conditions at local, national and international level) that affect continuity, b) examine the impact of these factors on continuity (all four criteria) also in relation to the boundaries set by the traditional parameters of continuity and in accordance with the original function of the site, $\mathrm{c}$ ) examine the consequences of this impact on the conservation and management of the site, and d) suggest ways to manage this evolution of continuity in the present/future, as well as its impact on the conservation and management of the site in the present/future. A living heritage approach would apply to Meteora in the following terms: a) the factors that affect the continuity of the Orthodox Tradition at the site: the breaking out of WWII and the Civil War, the birth of the philanthropic-missionary approach to monasticism by the 'ecclesiastical organisations', and the development of heritage and tourism industries, b) the impact of these factors on continuity: the separation between monasticism, heritage protection and tourism development; an increased emphasis on tourism; and the adjustment of monasticism to the pressure of tourism. These are not strictly within the principles of the Orthodox Tradition at the site. c) consequences on the conservation and management of the site: for example, the absence of a unified management mechanism, unauthorised construction activity on the site, and continually changing spatial arrangements with buildings of interwoven and conflicting functions. d) the proposed solution: an increased emphasis on the principles of the Orthodox Tradition, marking a shift from developing tourism to worshipping God, and incorporating tourism development and heritage protection within monasticism; also, the operation of the Holy Assembly so that unified management of the site is achieved.

It is important to note, however, that a living heritage approach would not aim at maintaining the continuity of the site at all cost and under any conditions. If the broader changing conditions at a local, national and international level affect continuity beyond the boundaries as set by the traditional parameters of continuity and outside the original function of the site, then a living heritage site will eventually become a site with a changing/evolving community (i.e. a community using a site in a different context to the original one, in response to the changing conditions, requirements and values of the society: see Part 1). In such cases, a living heritage approach as a unified approach may no longer apply to the specific site; yet, certain of its tools (eg. the four 
criteria of continuity) may still be useful for the understanding of the (new) community's association with the site and the impact of this association on the conservation and management of the site (see Poulios 2012a, 134-139).

\section{Conclusion}

Conservation in the context of a living heritage approach primarily aims at the maintenance and enhancement of continuity, and safeguards heritage within this connection even if in certain occasions the fabric might be harmed. Conservation also aims at embracing evolution/change over time, and thus guaranteeing the relevance of heritage to the contemporary society.

A living heritage approach facilitates a clearly community-centred, interactive and bottom up approach to conservation in assessing the significance of heritage based on core community's connection with heritage, and developing activities for the continuous care of heritage using traditional (or established) mechanisms and practices.

Therefore, a living heritage approach calls for the safeguarding of heritage within the connection of the present community with heritage (continuity), by the present community and for the sake of the present community. Emphasis is on the present, since 'the past is in the present' (Wijesuriya 2005; Poulios 2008). The starting point as well as the focal point in the conservation process is the present: present is seen as the continuation of the past into the future, and thus past and presentfuture are unified into an ongoing present. 